DOI 10.37882/2223-2982.2021.09-2.01

\title{
ПОЛИТИЧЕСКИЙ РАДИКАЛИЗМ В ДЕЯТЕЛЬНОСТИ НТС В РЕСПУБЛИКЕ КОРЕЯ В 1950-1960-Е ГГ:: ОСНОВНЫЕ ИСТОРИЧЕСКИЕ ИСТОЧНИКИ'
}

\section{POLITICAL RADICALISM \\ IN THE ACTIVITIES OF NTC IN THE REPUBLIC OF KOREA IN 1950-1960S: MAIN HISTORICAL SOURCES}

\section{A. Antoshin \\ V. Antoshin}

Summary: The article presents an analysis of the main historical sources on the history of the People's Labor Union (NTS) in the Republic of Korea in the 1950s-1960s. The main attention is paid to such groups of sources as periodicals, ego-documents, speeches of NTS figures. The archival sources on the history of the NTS are analyzed, in particular, those stored in the Archives of the Center for Eastern European Studies, University of Bremen (Germany). The authors argue that a significant part of the sources on this topic are in the public domain and are not yet available to researchers.

Keywords: Russian emigres, NTS, South Korea, Cold War, Asian People`s Anti-Communist League.

\section{Антошин Алексей Валерьевич}

Д.и.н., профессор, Уральский Федеральный Университет

Антошин Валерий Алексеевич

К.ф.н., профессор, Уральский Институт Управления

PAHXUГC

alex_antoshin@mail.ru

Аннотация: В статье представлен анализ основных исторических источников по истории Народно-трудового союза (НТС) в Республике Корея в 1950-1960-е гг. Основное внимание уделено таким группам источников, как периодическая печать, эго-документы, выступления деятелей НТС. Анализируются архивные источники по истории НТС, в частности, хранящиеся в Архиве Центра восточноевропейских исследований Университета Бремена (Германия). Авторы доказывают, что значительная часть источников по данной теме находятся в закрытом доступе и пока не доступны исследователям.

Ключевые слова: русская эмиграция, НТС, Южная Корея, холодная война, Антикоммунистическая лига народов Азии. роблематика истории русской эмиграции в Республике Корея в XX в. относится к числу слабо изученных в историографии сюжетов. Русская диаспора в этой стране была крайне немногочисленной, Корея не относилась к крупным центрам Русского зарубежья. Характерно, что в основательном каталоге собрания Библиотеки имени Гамильтона Гавайского университета (Гонолулу, США), составленном П. Полански при участии А.А. Хисамутдинова, имеется всего лишь одна книга, изданная русскими эмигрантами в Корее. Это - сборник произведений поэтессы В.Ю. Янковской (1909-1996) «Это было в Корее...», изданный в 1935 г. [3, с. 185]. Именно семья Янковских во многом олицетворяла русскую эмиграцию в оккупированной Японией Корее 1920-1930-х гг. Интересный анализ феномена этой семьи, специфики того варианта адаптации, который был ею выбран, содержится в недавно вышедшем исследовании С.В. Смирнова [7].

Вторая мировая война радикально изменила ситуа- цию на Корейском полуострове. Как известно, одним из ее итогов стал разгром Японии, освобождение территории Кореи советскими и американскими войсками. Однако уже в середине 1940-х гг. Корея стала ареной противостояния сверхдержав, стремившихся использовать внутриполитические противоречия на полуострове в своих целях. Все это привело к событиям Корейской войны 1950-1953 гг., окончательно расколовшим страну на две части.

Оба возникших в середине XX в. корейских государства не относились к числу стран с демократическими политическими режимами. Их идеологические установки были противоположны, однако оба они мало соответствовали западным представления о свободе и демократии. Авторитарный антикоммунизм в Южной Корее стал важной основой для проведения ускоренной социально-экономической и политической модернизации страны. Вместе с тем политическая элита южнокорейского режима оказывала разнообразную помощь антикомму-

1 Исследование выполнено в рамках гранта РФФИ № 19-59-51004 «Роль диаспоральных сообществ в социально-экономическом и культурном развитии России и Кореи в XXв. (на материалах сообществ русских эмигрантов в Корее и корейской общины Урала)». 
нистическим силам, действовавшим в регионе. Эти силы воспринимались местными политиками во многом как противовес влиянию СССР и КНР, поддерживавших режим КНДР. Среди этих сил были и русские антикоммунисты, прежде всего, входившие в состав Народно-трудового союза (НТС), история которого уже нашла свое отражение в историографии [1 и др.].

Однако, следует учитывать, что в Республике Корея 1950-1960-х гг. НТС вынужден был действовать в сложных условиях. Еще в 1930-е гг. Союз был известен как молодежная русская эмигрантская группа в Европе и Азии, в деятельности которой были сильны праворадикальные и даже экстремистские тенденции. Деятели НТС отстаивали концепцию «национальной революции» в СССР как результата народного восстания. В годы Второй мировой войны эта организация тесно сотрудничала с нацистами, участвовала в возникновении Русской освободительной армии (РОА) генерала А.А. Власова. Все это сформировало негативный имидж НТС как полуфашистской экстремистской группировки, который умело использовался советским пропагандистским аппаратом. В случае активизации деятельности НТС в какой-либо стране советские дипломаты заявляли ее правительству протест. Именно поэтому руководство Республики Корея, очевидно, отнюдь не стремилось афишировать тот факт, что русские антикоммунисты действовали на ее территории. Это обстоятельство вело к тому, что в распоряжении исследователей имеется крайне мало источников, посвященных истории организации НТС в Республике Корея.

Важнейшим историческим источником такого рода является еженедельник «Посев», который являлся наиболее известным изданием НТС эпохи холодной войны. Ведущий специалист по истории издательской деятельности политических организаций русской эмиграции П.Н. Базанов отмечает, что позицией редакции «Посева» была «поддержка всех форм антикоммунизма в мире, и, в меньшей степени, российских национально-государственных интересов» [2, с. 326]. Как справедливо указывает петербургский историк, «утилитарные агитационно-пропагандистские задачи, стоявшие перед еженедельником «Посев», повлияли на характер материалов на его страницах. Они давались в очень доступной форме, понятной для любой читательской аудитории» [2, с. 326]. Нередко материалы, публиковавшиеся на страницах «Посева», современными исследователями могли бы быть отнесены к разряду экстремистской литературы.

Именно Представительство Издательства «Посев» и было наиболее значимой русской эмигрантской политической организацией в Республике Корея эпохи холодной войны. Впервые информация о нем появилась на страницах «Посева» в январе 1959 г. При этом перво- начально открыто указывался как адрес Представительства в Сеуле, так и личность руководителя этой структуры Рудольфа Парккали [4]. Однако с середины октября 1959 г. данные о Представительстве становятся гораздо более скупыми: в «Посеве» стали указывать в качестве адреса этой структуры лишь № 59 абонентского ящика Международной почты в Сеуле [5]. Очевидно, стремление руководства НТС скрыть конкретную информацию о данном Представительстве диктовалось спецификой этой организации. Как указывает, в частности, известный американский историк Б. Тромли, НТС в годы холодной войны был тесно связан с ЦРу, деятельность русской эмигрантской организации финансировалась американской спецслужбой [9].

Главным направлением деятельности НТС в Республике Корея было участие в конференциях Антикоммунистической лиги народов Азии. Данная структура была основана в 1954 г. в результате состоявшейся в Южной Корее встречи Президента Республики Корея Ли Сын Мана и руководителя Тайваня Чан Кайши. К концу 1950-х гг. в составе Лиги, кроме Южной Кореи и Тайваня, были также представители Вьетнама, Филиппин, Гонконга, Макао, островов Риу-Киу, Малайи, Сингапура, Бирмы, Таиланда, Австралии, Новой Зеландии. Более того: к Лиге присоединились даже антикоммунисты Пакистана, Ирана и Турции, чьи страны находились довольно далеко от государств-основателей организации. В качестве наблюдателей в Лиге участвовали и деятели НТС, выступавшие от имени антикоммунистической России. На конференциях Лиги они имели совещательный голос.

Именно Республика Корея, наряду с Тайванем, была одним из главных центров деятельности данной организации, поэтому ряд конференций Лиги прошел именно в Сеуле. Еженедельник «Посев» широко освещал конференцию, прошедшую в 1959 г. Опубликованные на страницах «Посева» отчеты о данном мероприятии показывают: руководству НТС очень важно было показать, что русских эмигрантов лидеры антикоммунистических сил Азии рассматривают как равноправных партнеров. В годы холодной войны деятели НТС пытались позиционировать себя как представителей альтернативной, Зарубежной России, которая имела даже подобие своей «внешней политики». Конференции Антикоммунистической лиги народов Азии должны были служить доказательством наличия такой «внешней политики», свидетельством признания Русского зарубежья во всем мире. Подчеркивалось, в частности, что в ходе конференции 1959 г. деятели НТС могли общаться и с руководителями Республики Корея, и с корейской интеллигенцией, включая профессоров и студентов университетов.

Интересным источником по истории деятельности НTC в Корее является опубликованная в № 26 «Посева» 
от 28 июня фотография, на которой изображены президент Республики Корея Ли Сын Ман с супругой, ректор Сеульского университета, один из индонезийских антикоммунистов, а также два русских эмигранта - видный деятель НТС Р.Н. Редлих и некий «корреспондент «Посева» Райкин». Последняя фигура загадочна: очевидно, это псевдоним, но раскрыть его пока не удалось. Данный визуальный источник весьма любопытен: появление данной фотографии и специфика подписей под ней являются своеобразным символом эпохи холодной войны.

Не менее значимым, чем «Посев», историческим источником по истории НТС в Республике Корея являются мемуары видного деятеля Союза Г.А. Рара (1922-2006), опубликованные в московском издательстве «Русский путь» в 2011 г. Глеб Александрович Рар родился в Москве в семье офицера Русской Императорской армии. В 1924 г. семья была выселена в Эстонию, затем они переселились в Латвию. Вырос в Лиепае (Либаве). В 1941 г. как балтийский немец переселился в Германию. Член НТС с 1942 г., в 1944-1945 гг. находился в заключении в концлагерях Заксенхаузен, Бухенвальд, Дахау и др., освобожден в апреле 1945 г. После войны работал в издательстве «Посев», в Отделе иностранных дел НТС во Франкфурте, на радиовещании НТС на Тайване и в Японии. С середины 1970-х гг. он - сотрудник радио «Свобода», ведущий религиозно-исторических передач. Г.А. Рар был председателем Свято-Князь-Владимирского Братства в Германии, членом Совета НТС в 1967-1990 гг.

В Республике Корея Г.А. Рар был дважды, в 1961 и 1962 гг. В 1961 г, по его словам, он отправился в Сеул, чтобы познакомиться с членами русской редакции Корейского радио, представиться руководителям Корейского отдела Антикоммунистической лиги, а также «составить себе хоть какое-то представление о перспективах развития деятельности НТС в Корее» [6, с. 400]. В 1962 г. он участвовал в работе конференции Антикоммунистической лиги, посетив в ходе этого мероприятия торжества по случаю годовщины вступления в должность Президента Пак Чжон Хи.

Мемуары Г.А. Рара содержат интересную информацию не только о тех условиях, в которых пришлось действовать членам НТС в Республике Корея в 1950-1960-е гг., но и о самих этих людях. Какую-либо информацию о деятелях НТС часто бывает найти весьма непросто, специфика деятельности этих людей накладывала свой отпечаток на их личности и биографии. Тем ценнее те характеристики, которые содержатся в мемуарах Г.А. Рара. Так, отмечая, что, скорее всего, Парккали - не настоящая фамилия уже упоминавшегося руководителя Представительства Издательства «Посев» в Республике Корея, Г.А. Рар так описывал его судьбу: «Чуть ли не из беспризорников, рос без семьи. Ленинградский паренек, о котором некому было заботиться. Человек по природе порядочный и здравомыслящий. В финскую войну был призван, попал в плен. Сумел доказать свое «ингерманландское происхождение». Благодаря этому избежал послевоенной судьбы советских пленных остальных национальностей - выдачи их советской стороне и отправки в сталинские лагеря за «измену родине» [6, с. 371]. Таким образом, Р. Парккали был довольно типичным эмигрантом «второй волны». Эпоха сталинской модернизации 1930-х гг. привела к разрушению многих социальных связей, часть людей оказались выброшены на обочину жизни советского общества. Именно такие люди, не пустившие «корней» в СССР, не имевшие семьи, чаще, чем другие, принимали решение остаться на Западе.

Существуют и архивные источники, посвященные деятельности НТС в Республике Корея в годы холодной войны. Так, большой интерес представляет Архив Центра восточноевропейских исследований Университета Бремена (Германия), где хранится личный фонд Г.А. Рара. В нем находятся тезисы доклада Г.А. Рара на тему «Деятельность НТС», сделанного в начале 1960-х гг. в ходе одного из визитов в Сеул. В данном докладе русский антикоммунист знакомил южнокорейских слушателей с основными направлениями деятельности его организации (очевидно, большинство посетителей лекций Г.А. Рара услышали о ней впервые). Он рассказывал о том, как НТС осуществлял заброску агентов в Советский Союз, вел пропаганду своих идей среди населения СССР (при этом рекламировалась практика создания ревкомов на кораблях советского торгового флота, которую многие эмигранты считали мистификацией). Упоминалось в докладе и о вещании радиостанции «Голос Свободного Китая» с территории Тайваня. Однако, основное внимание Г.А. Рар, конечно, уделил южнокорейскому проекту НTC - вещанию радиостанции «Свободная Россия» с территории Республики Корея на советский Дальний Восток. Оно осуществлялось около 10 лет, в 1959-1969 гг., в виде ежедневных 20-минутных передач.

Не мог не упомянуть Г.А. Рар в своем выступлении и об еще одном направлении деятельности НТС, которое косвенно оказалось связано именно с Южной Кореей. В этой стране в 1955 г. упал 20-метровый баллон, изготовленный специальной группой НТС в Бад-Гомбурге (ФРГ). Эта конструкция поднимала около 90 килограммов антикоммунистических листовок, которые сбрасывались каждые 400-500 км по пути полета баллона. История с падением баллона имела резонанс, и Г.А. Рару пришлось объяснять, какие цели преследовал НТС, запуская эти устройства. «Зовем к сопротивлению и к подготовке переворота» [8], - заявил он.

Как свидетельствуют архивные источники, Г.А. Рар 
заканчивал свой доклад, объясняя слушателям причины своего пребывания в Республике Корея: «Невозможность антикоммунистической революции только в одной Корее, как в Венгрии. Центр (язва) в Москве. Если будет революция в Советском Союзе, некому будет посылать войска на подавление. Только в совместном действии обретем мы победу» [8] - подчеркивал он.

Заканчивая краткий обзор источников по истории деятельности НТС в Республике Корея в годы холодной войны, следует отметить, что их комплекс пока весьма ограничен. Данное обстоятельство связано, бесспорно, не только с тем, что Южная Корея не была ведущим центром Русского зарубежья, но и с особенностями деятельности НТС. Тесная связь этой организации со спецслужбами ведет к тому, что значительная часть информации о ней находится пока в закрытом доступе. Так, известно, что документы по данной теме имеются в Национальном архиве Кореи (подразделение в г. Пусан). Однако иностранные исследователи пока не получали доступ к этим материалам.

ЛИТЕРАТУРА

1. Алексеев Д.Ю. НТС российских солидаристов в борьбе против тоталитарного режима: Автореф.дис. .. канд.ист.наук. Владивосток, 1998. 22 с.

2. Базанов П.Н. Издательская деятельность политических организаций русской эмиграции (1917-1988 гг.). СПб.: СПБГУКИ, 2008. 468 с.

3. Полански П. Русская печать в Китае, Японии и Корее. М.: Пашков дом, 2002. 204 с.

4. Посев. Франкфурт-на-Майне, 1959. № 4.25 января. С. 10.

5. Посев. 1959. № 41.11 октября. С. 10.

6. Рар Г.А. «...И будет наше поколенье давать истории отчет». Воспоминания. М.: Русский путь, 2011. 728 с.

7. Смирнов С.В. Семья Янковских: социальная адаптация русских эмигрантов в Корее (1920-е - начало 1940-х гг.) // Известия Уральского федерального университета. Серия 2. Гуманитарные науки. 2021. № 1. С. 99-113.

8. Forschungsstelle Osteuropa an der Universitat Bremen. Historisches Archiv (FSO UB. HA). F. 106 (Rahr Gleb). Доклад «Смена поколений в СССР».

9. Tromley B. The Making of a Myth: The National Labor Alliance, Russian Emigres, and Cold War Intelligence Activities // Journal of Cold War Studies. 2016. Vol. 18. Issue 1. P. 80-111.

(с) Антошин Алексей Валерьевич, Антошин Валерий Алексеевич (alex_antoshin@mail.ru).

Журнал «Современная наука: актуальные проблемы теории и практики»

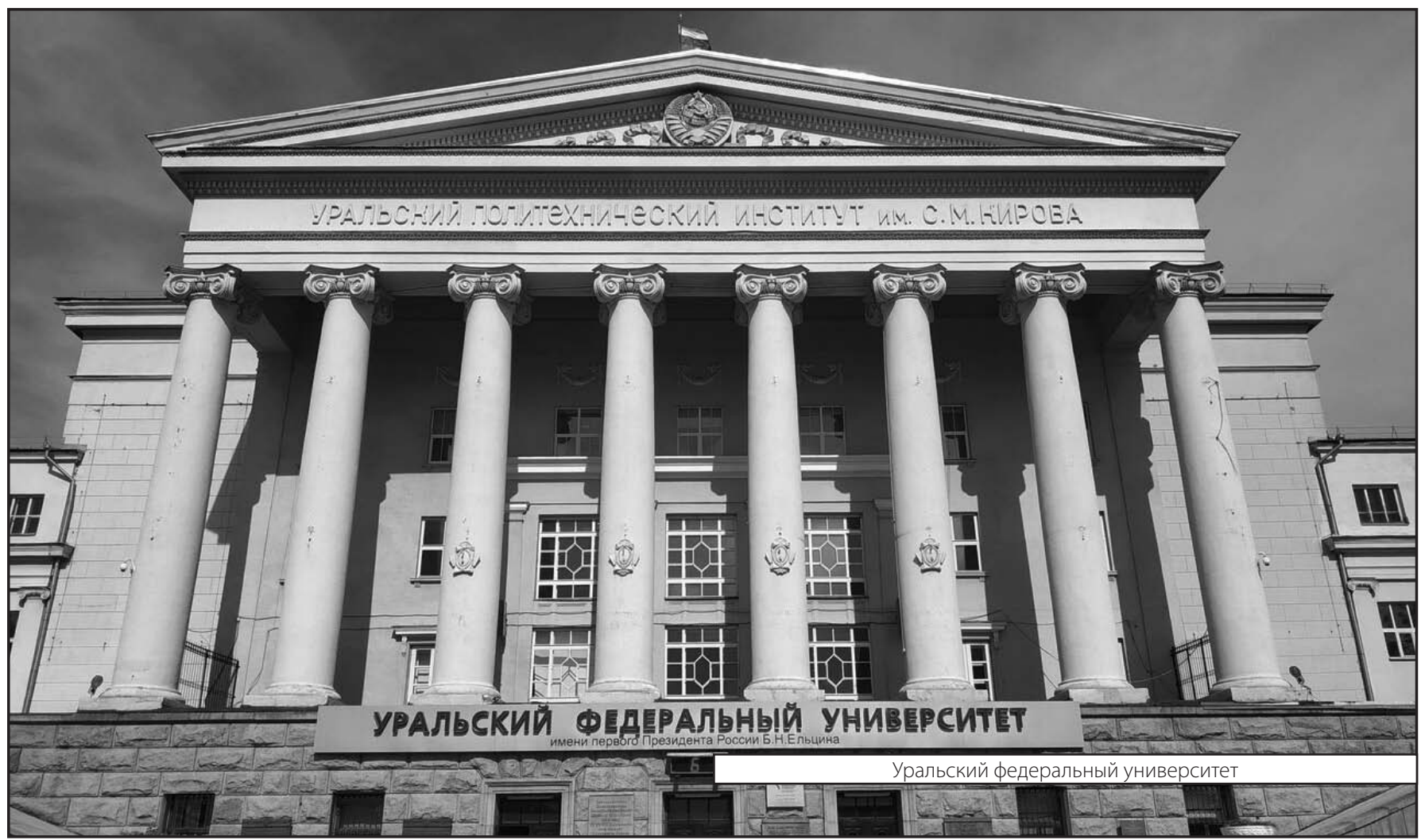

